\title{
Smoke free site and service awareness amongst hospital staff: a survey in an acute cancer centre
}

\author{
Peter Mackereth , Maycock Paula, Orrett Linda \\ Complementary Health \& Wellbeing Services, Rehabilitation Unit, The Christie NHS Foundation Trust, Manchester, UK
}

Received: December 11, 2014

Accepted: January 14, $2015 \quad$ Online Published: February 2, 2015

DOI: $10.5430 /$ jha.v4n2p43

URL: http://dx.doi.org/10.5430/jha.v4n2p43

\begin{abstract}
The purpose of our survey was to identify the awareness of the smoking cessation policy and smoking habits of staff within the hospital. Hospital employees were asked to complete a short questionnaire on their awareness of the smoking cessation policy and their smoking habits. A total of 325 members of staff completed the questionnaires. $99 \%$ of respondents were aware of the hospital site being smoke free. There was less awareness around smoking cessation services for staff, patients and caregivers. There were 23 current smokers, of which 12 expressed interest in stopping smoking. The sample was $13 \%$ of the total workplace and our plans are to promote and repeat the survey in 2015.
\end{abstract}

Key Words: Employees, Hospital site, Smoke-free, Survey

\section{Introduction}

Smoke free hospital campuses have only recently been introduced in the UK. This article reports on responses from staff working at a major cancer centre. We aimed to gather for the first time awareness of the site's smoke free status and services available. The survey was distributed to staff and volunteers via the hospital intranet, the staff annual "health and well-being" day and on induction and mandatory training days.

\subsection{Smoking cessation and cancer care}

Smoking is the major cause of preventable morbidity and premature death, accounting for in excess of 80,000 deaths in England in 2009, some 18 per cent of all adult deaths (aged 35 plus). ${ }^{[1]}$ Smoking causes a range of illnesses and disability, most become apparent after years of smoking. In 2009, 35 per cent of all deaths in England were from respiratory diseases and 29 per cent of deaths from cancers were attributed to smoking. ${ }^{[1,2]}$ It is important to offer smoking cessation to family and friends of smokers to increase quitting in the wider community and reduce cancer rates. Smoking Cessation Advisors in UK hospitals are taking a lead on promoting and sustaining smoke-free and health promoting environments; with interventions directed at patients, visitors and staff. It is now recognised that hospital visits and stays provide an opportunity for clinical staff to identify and assist patients to stop smoking, and so reduce treatment side-effects and promote recovery. ${ }^{[3,4]}$ This article reports on a recent survey conducted with staff working in a major cancer hospital.

During cancer treatment, smoking status may not be identified and/or effectively addressed at treatment planning stage. The reasons for this can include patients not disclosing or were not asked about their smoking status, or patients may not have prioritised cessation or are not fully informed of the hazards of continuing during cancer treatment. A lit-

\footnotetext{
* Correspondence: Peter Mackereth; Email: peter.mackereth@christie.nhs.uk; Address: Smoking Cessation Services Rehabilitation Unit, The Christie NHS Foundation Trust. Wilmslow Rd. Manchester, UK.
} 
erature review on cancer and smoking reports that many of the chemicals found in the smoke interfere with clinical efficacy of chemotherapy and radiotherapy; both of these medical treatments work best in oxygen rich tissue. ${ }^{[5]}$ Carbon monoxide, found in smoke, can make nausea worse and impairs circulation. Importantly, quitting can help to reduce risk of metastatic disease and new primaries. In addition, tar found in smoke is known to interfere with metabolism of drugs, again undermining treatment efficacy. Smoking cessation has been found to positively help with extending survival time in patients diagnosed with early stage lung cancer. $^{[6]}$ In patients with breast cancer, smoking cessation is associated with lower risk of lung primaries and further metastatic disease. For those patients who continue to smoke following radiotherapy treatment for lymphomas and testicular cancers there is a higher risk of lung primaries. ${ }^{[7-9]}$

\subsection{Service provision}

At the Christie, smoking cessation (SC) services are provided by the Clinical Lead for Supportive Care and Tobacco Control and 5 part-time advisors, all trained by the Manchester Stop Smoking Service. The smoking cessation package includes: assessment and advice, nicotine replacement therapy (NRT) provision, motivational interviewing and stress management techniques. These interventions are well supported by both NICE guidelines and Cochrane reviews. ${ }^{[10-12]}$ Currently, patients and caregivers (e.g. family, partners and close friends) at The Christie can also access acupuncture and hypnotherapy, free at the point of delivery. These therapies are provided as secondary interventions based on the evidence that they can be helpful adjuncts rather than replacements for NRT and conventional smoking cessation support. ${ }^{[13,14]}$ These services are funded from charitable sources.

\subsection{Staff training}

It is recommended by $\mathrm{NICE}^{[15]}$ that all health professionals be able to:

- Provide brief information about smoking cessation

- Signpost patients, caregivers and colleagues to local SC services

- Record patient's smoking status

- Enquire whether the person would like help in stopping smoking

- Indicate benefits of stopping smoking to his/her health and wellbeing

Since September 2007 the SC team have been delivering monthly Brief Interventions Training for hospital staff as recommended by NICE. ${ }^{[15]}$ To date over 270 people have voluntarily attended the programme, including doctors, nurses and radiographers. The SC team provide information and support on the National No Smoking and World
Tobacco Free Days each year, as well as other events (e.g. Open day and Lung Week).

In the last 12 months the SC team have provided in excess of 900 sessions either as a one-to-one session in clinics, on the wards or at our twice weekly drop-in sessions in the Rehabilitation Unit. In addition we also provide short information sessions to patients and caregivers seen smoking on site. The team has developed an information leaflet and established a smoking cessation telephone helpline. Additionally, we have been prescribing NRT for caregivers as part of a charity funded project. The SC service is monitored by Manchester Stop Smoking with all referrals, advice and treatment sessions documented. All therapists work closely with Manchester's Stop Smoking Service, the Occupational Health Department and all hospital staff and volunteers to maximise this therapeutic approach to smoking cessation for patients and caregivers.

\section{The survey}

With the assistance of the audit department, a smoking cessation questionnaire was developed and distributed to staff and volunteers on a wellbeing day and on the hospital's intranet. The survey aimed to gather information about:

- The prevalence of smoking amongst staff

- Awareness of the site being "smoke free"

- Interest and/or previous attendance at the brief interventions training

Additionally, those that were smokers were asked about interest in seeking support to quit. The survey was also instigated as a means of raising the profile of the smoking cessation service.

\section{Results}

Three hundred and twenty-five questionnaires were completed voluntarily. A range of staff completed the form with nurses (40\%) and radiotherapy staff (19\%) being the largest groups represented (see Table 1). The sample represents approximately $13 \%$ of the total workforce. The Christie hospital site has been a smoke free site since 2005 . Ninety nine per cent of the sample reported awareness of the site being smoke free. Seventy two (22\%) were not aware that being found smoking on site or close by in uniform/identity badge could lead to disciplinary action (see Table 2).

\subsection{Services for patients and staff}

Two hundred and fifty-four (78\%) respondents confirmed that they were aware of The Christie SC service for patients and caregivers and $222(68 \%)$ were aware that it was also available for staff and volunteers (see Table 2). 
Table 1: Demographical information $(n=325)$

\begin{tabular}{|c|c|c|c|}
\hline & Item & Number & Percentage \\
\hline \multirow{2}{*}{ Sex } & Female & 256 & $79 \%$ \\
\hline & Male & 69 & $21 \%$ \\
\hline \multirow{6}{*}{ Age Range } & $20-30$ & 102 & $31 \%$ \\
\hline & $31-40$ & 89 & $27 \%$ \\
\hline & $41-50$ & 82 & $25 \%$ \\
\hline & $51-60$ & 44 & $14 \%$ \\
\hline & $61-70$ & 5 & $2 \%$ \\
\hline & $71+$ & 3 & $1 \%$ \\
\hline \multirow{9}{*}{$\begin{array}{l}\text { Professional } \\
\text { Role }\end{array}$} & Nursing & 130 & $40 \%$ \\
\hline & Radiotherapy & 62 & $19 \%$ \\
\hline & Other & 46 & $14 \%$ \\
\hline & Medical & 32 & $10 \%$ \\
\hline & Admin/IT & 28 & $9 \%$ \\
\hline & Physio & 10 & $3 \%$ \\
\hline & Research & 10 & $3 \%$ \\
\hline & Domestic/Porter & 5 & $2 \%$ \\
\hline & Occupational Therapy & 2 & $1 \%$ \\
\hline
\end{tabular}

\subsection{Smoking status}

Two hundred and eighty respondents $(86 \%)$ reported that they did not smoke, with $53(16 \%)$ of those being exsmokers. Of the 23 current smokers, $10(3 \%)$ reported that they had "no intention of stopping smoking". Twelve (57\%) smokers said they would consider using smoking cessation services provided on-site with 4 (17\%) additionally stating they would consider using services off-site (see Table 3).

\section{Discussion}

This was the first survey at the site providing a snapshot of awareness amongst staff and a small number of volunteers of smoking cessation issues/concerns. There appears to be wide awareness of the hospital being a smoke free site, and of the availability of smoking cessation services for patients and staff and the disciplinary policy.

In the Greater Manchester area approximately 37\% of the population smoke, this is higher than the national average $(21 \%) .^{[1,16]}$ It is important to acknowledge the sample was just 325 and may not be representative of the wider workforce at the Trust. It is likely that smokers would not openly visit a smoking cessation stand if their status was not known to colleagues or if they did not want to stop smoking.

The low numbers of smokers participating in the survey means that the data is insufficient to make any interpretation or recommendations. There is a need to gather more detailed data from one-to-one interviews or focus groups with smokers about their experience of accessing services and what might or might not be useful. Again, smokers not wanting to disclose their status would be unlikely to participate. Anecdotally some of our service users have commented that they have a degree of shame around their smoking. Following this survey there is a need to:

Table 2: Awareness of smoke - free site \& services $(n=325)$

\begin{tabular}{|c|c|c|c|}
\hline Question & Answer & Number & Percentage \\
\hline \multirow{2}{*}{ Awareness of The Christie being a "Smoke Free" site? } & Yes & 321 & $99 \%$ \\
\hline & No & 4 & $1 \%$ \\
\hline \multirow{2}{*}{$\begin{array}{l}\text { Awareness of smoking on site/in uniform being a disciplinary } \\
\text { issue? }\end{array}$} & Yes & 253 & $78 \%$ \\
\hline & No & 72 & $22 \%$ \\
\hline \multirow{2}{*}{$\begin{array}{l}\text { Has attended Smoking Cessation Brief Interventions Training } \\
\text { in the last three years? }\end{array}$} & Yes & 57 & $18 \%$ \\
\hline & No & 268 & $82 \%$ \\
\hline \multirow{3}{*}{ Would you like to attend SC Brief Interventions Training? } & Yes & 70 & $26 \%$ \\
\hline & No & 156 & $58 \%$ \\
\hline & Not answered & 42 & $16 \%$ \\
\hline \multirow{3}{*}{ Aware of Free Smoking Cessation Service for Patients? } & Yes & 254 & $78 \%$ \\
\hline & No & 50 & $15 \%$ \\
\hline & Not answered & 21 & $6 \%$ \\
\hline \multirow{3}{*}{ Aware of Free Smoking Cessation for Staff/Volunteers? } & Yes & 222 & $68 \%$ \\
\hline & No & 76 & $23 \%$ \\
\hline & Not answered & 27 & $8 \%$ \\
\hline
\end{tabular}

- Repeat the questionnaire annually

- Provide information about the Brief Interventions Training in the questionnaire preamble, alerting staff to how this can be accessed

- Increase the number of responses to future surveys to ascertain more clearly numbers of the smokers and the views of groups not represented in this survey

- Disseminate the findings and recommendations/issues arising to staff and volunteers

- Target specific professional groups working in front- 
line services when promoting Brief Interventions Training

- Include questions around accessing services off site locally, exposure to passive smoking and the provision of services to members of staffs' family

An area for further research is the effectiveness of Brief In- terventions Training for frontline staff. Attending training is a first step, however having the confidence to ask patients about their smoking status, articulate appropriate and specific health benefits and initiate referrals is more complex. Identifying factors and processes to enable staff to translate the training into best practice could be uncovered by observational and qualitative enquiry.

Table 3: Smoking status of staff \& interest in support to quit

\begin{tabular}{llll}
\hline Question & Answer & Number & Percentage \\
\hline & Non-Smoker & 227 & $70 \%$ \\
Which describes your smoking status best? & Ex-Smoker & 53 & $16 \%$ \\
$(\mathrm{n}=325)$ & Smoker - does not want to stop & 10 & $3 \%$ \\
& Smoker - would like to stop & 12 & $4 \%$ \\
& Not answered & 23 & $7 \%$ \\
Would you participate in smoking cessation & Yes & 13 & $57 \%$ \\
assistance on-site? ( $=23)$ & Not sure & 4 & $17 \%$ \\
& Not answered & 0 & $0 \%$ \\
Would you participate in smoking cessation & Yes & 6 & $26 \%$ \\
assistance off-site? (n = 23) & No & 4 & $17 \%$ \\
& Not sure & 3 & $13 \%$ \\
& Not answered & 12 & $17 \%$ \\
\end{tabular}

\section{Conclusions}

Smoke free hospitals are a relatively new concept in the UK and from anecdotal communications with colleagues in the North West, not always respected by all visitors, patients and staff. It needs to be acknowledged that it may take time and education to achieve observable "smoke free" hospital campuses. It is important to report that the smoking cessation team has seen a rise in the number of patient referrals and self referrals from staff. This raises the possibility that conducting the survey itself may have influenced practice. Other possibilities may include:

- A smoke free environment led to a desire to quit

- The smoker and environment increased guilt or attention on smokers

- The increased awareness of free smoking cessation programs and support
It should be noted that these results may have been influenced by the fact that this research site was a cancer centre where people may be more aware of the need to stop smoking. Therefore this survey may not directly reflect the results that might be seen of smoke free campus at a general hospital or a non-medical site. This survey will be repeated next year and it is hoped that the information will assist us in developing and promoting the service with staff, patients and caregivers.

\section{Acknowledgements}

We would like to thank the survey respondents for their valued contribution to this project.

\section{Conflicts of Interest Disclosure}

The authors declare that they have no competing interests.

\section{References}

[1] NHS Information Centre. Statistics on Smoking: England. NHS Information Centre, Leeds. 2010.

[2] Do H. Healthy Lives, Healthy People: A Tobacco Control Plan for England. Department of Health Tobacco Programme. 2011; 133155. PMid:21676583.

[3] Jones K. Ward off the smoking addiction. The Advisor Spring Edition. $2011 ; 2(1)$ : 6-7.

[4] Williams SC, Morton DJ, Jay KN, Koss RG, Schroeder SA, Loeb JM . Smoking cessation counseling in U.S. hospitals: a comparison of high and low performers. J Clin Outcomes Manage. 2005; 12(7): 345-352.

[5] Ostroff JS, Dhingra LK. Smoking Cessation and Cancer Survivors. In: Feverstein M (Ed) Handbook of Cancer Survivorship. Springer, New York. 2007. http://dx.doi.org/10.1007/978-0-387-3 4562-8_17

[6] Parsons A, Daley A, Begh R, Aveyard P. Influence of smoking cessation after diagnosis of early stage lung cancer on prognosis: sys- 
tematic review of observational studies with meta-analysis. BMJ. 2010; 340: b5569. PMid:20093278. http://dx.doi.org/10.11 $36 / \mathrm{bmj}$. b5569

[7] Mudie, NY, Swerdlow AJ, Higgins CD, Smith P, Qiao Z, Hancock $\mathrm{BW}$, et al. Risk of second malignancy after non-Hodgkin's lymphoma: a British Cohort Study. J Clin Oncol. 2006; 24(10): 156874. PMid:16520465. http://dx.doi.org/10.1200/JCD. 2005. 04.2200

[8] Lorigan P, Radford J, Howell A, Thatcher N. Lung cancer after treatment for Hodgkin's lymphoma: a systematic review. Lancet Oncol. 2005; 6(10): 773-9. http://dx.doi.org/10.1016/S1470-204 5 (05) $70387-9$

[9] Travis LB, Fosså SD, Schonfeld SJ, McMaster ML, Lynch CF, Storm H., et al. Second cancers among 40,576 testicular cancer patients: focus on long-term survivors. J Natl Cancer Inst. 2005; 97(18): 1354-65. PMid:16174857. http://dx.doi.org/10.10 93/jnci/dji278

[10] Stead LF, Perera R, Bullen C, Mant D, Lancaster T. Nicotine replacement therapy for smoking cessation. Cochrane Database of
Systematic Reviews Issue 1 Art. No.: CD000146. 2008.

[11] Rigotti NA, Munafo MR, Stead LF. Interventions for smoking cessation in hospitalised patients. Cochrane Database of Systematic Reviews. 2002; Issue 4. Art. No.: CD001837. http://dx.doi.org /10.1002/14651858. CD001837.pub2

[12] NICE. Technology Guidance No 38. Nicotine replacement therapy (NRT) and bupropion for smoking cessation. March 2002.

[13] Abbott, NC, Stead, LF, White, AR, Barnes, J. Hypnotherapy for smoking cessation. Cochrane Database of Systematic Reviews. 2008; Issue 4 Art. No.: CD001008.

[14] White AR, Rampes H, Campbell J. Acupuncture and related interventions for smoking cessation. Cochrane Database of Systematic Reviews. 2006; Issue 1. Art. No: CD000009. http://dx.doi.o rg/10.1002/14651858. CD000009.pub2

[15] NICE. Smoking Cessation Services. NICE Public Health Guidance NICE. February 2008.

[16] HAD The Smoking Epidemic in England. Health Development Agency. 2004. 